\title{
Surface and Intraparticle Diffusion of Crystal Violet Dye on Egyptian Doum Fruit from Aqueous Solutions
}

\author{
Ahmed A. Abdel- Khalek*a \\ Chemistry Department, Faculty of Science, \\ Beni-Suef University, Beni-Suef City, Egypt.
}

\author{
Mahmoud M. Abdel- Hafeez \\ Forensic Medicine Authority, Ministry of Justice, \\ Cairo, Egypt.
}

*a Author for correspondence

\author{
Reham A. Mohamed*b \\ Lecturer of physical chemistry - Faculty of Science, \\ Beni Suef University,
}

ORCID: 0000-0002-9220-9500

\author{
Engy H.Gabrail \\ Manager of Occupational Safety and Health Administration, \\ Beni-seuf University, Beni-seuf, Egypt.
}

${ }^{* b}$ Co-Author for correspondence waste water due to its simplicity, efficiency, fast, universal method and applicability, beside that it is inexpensive [2]. The main idea of the adsorption process is based on a partitioning of analyte between two phases, a solid phase (sorbent) and a liquid phase (sample matrix or solvent with analytes) [3]. The adsorption is influenced strongly by the used sorbent because it is controlled by many parameters such as selectivity, affinity and capacity [4]. So, the development of methodology of adsorption onto solid phases is connected by the introduction of novel types of sorptive materials.

A large number of sorbents are available now such as, polymer sorbents, graphitized or porous carbon and chemically modified silicagel. Due to the highly adsorption capacity of Activated Carbon (AC), it is used on a large scale for many years as an adsorbent for the removal of hazardous pollutants from water. The highly cost of producing and regeneration of $\mathrm{AC}$ encouraged the investigator on studying the possibility of using cheaper and available alternatives to AC adsorbent.

Low-cost, high distribution coefficients, high exchange capacity and availability, are the most important requirements for sorbents in the purification process. Up to day, the search focuses on developing low-cost adsorbents such as metal hydroxides sludge, natural materials, rock minerals, wood wastes, agricultural wastes or industrial to utilize as adsorbents [5]. Many agricultural waste materials have been extensively investigated [6-14]. Also, industrial wastes and natural substances are used [15-19]. The developing countries are needed to establish industries based on utilizing natural resources in various sectors. Doum palm (Hyphaenethebaica) is common in Upper Egypt, originally native to the Nile valley, bearing an edible fruit which has pharmacologic properties [20]. Extracts of Doum are used in the treatment of some diseases [21-23]. However, no researches have been carried on the ability of the DF to be a natural adsorbent to remove dyes from wastewater.

$\mathrm{CV}$ is a well-known triaryl methane cationic dye with 
molecular formula and molecular weight $\mathrm{C}_{25} \mathrm{~N}_{3} \mathrm{H}_{30} \mathrm{Cl}$ and $407.979 \mathrm{gm} / \mathrm{mole}$, respectively. It is used in various purposes in the industrial and medical fields [24]. In this research it is used as an adsorbate, a model molecule or as a representative for organic pollutants.

The main objectives of this study are to determine the effectiveness and feasibility of EDF in the removal of CV dye from aqueous solutions.

\section{EXPERIMENTAL}

\subsection{Preparation of adsorbate}

CV dye supplied by Aldrich was used as an adsorbate to determine the adsorption potential of EDF. The dye was used as such without any further purification. A stock solution of $\mathrm{CV}$ dye solution was prepared $(1000 \mathrm{mg} / \mathrm{L})$ by dissolving the $0.1 \mathrm{gm}$ of dye powder in double distilled water then diluted with double distilled water to obtain desired dye concentration.

\subsection{Preparation of adsorbent}

DF was collected from a farm in Upper Egypt, Fig. 1a. It is washed several times with distilled water to remove any environmental contaminations and dried in an oven at $60^{\circ} \mathrm{C}$ overnight after cutting it into small parts to remove the seed, Fig.1b. To obtain powder, a ball milling method was used where the small pieces of DF were milled by a high energy ball miller with a speed $170 \mathrm{rpm}$ for $10 \mathrm{~h} .21$ porcelain balls were used; 10 of them have $1.7 \mathrm{~cm}$ diameter and $9.9 \mathrm{~g}$ weight, the other 11 balls are $0.8 \mathrm{~cm}$ in diameter and $1.54 \mathrm{~g}$ weight. The DF was grounded and screened through a set of sieves to obtain particles of size $10-80 \mu \mathrm{m}$ then kept dry in a closed container until required. No chemical or physical treatments were performed prior to adsorption experiments, see Fig. 1c.

(a)

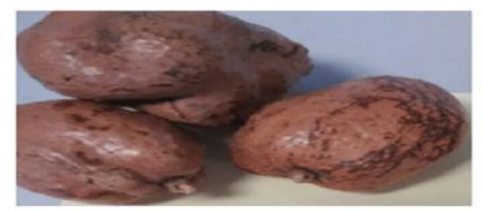

(b)

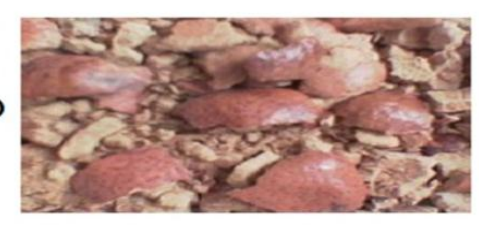

(c)

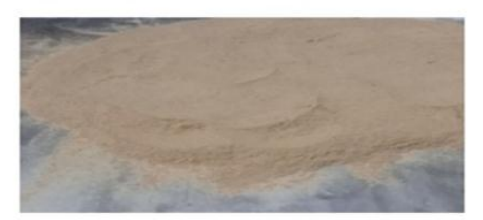

Fig. 1. a- DF b- DF after cutting to remove the seed c- DF powder.

\subsection{Adsorbents characterization}

The Fourier transform infrared (FT-IR) spectrum was recorded on a Vertex 70 FT-IR instrument (Bruker Company). The sample was thoroughly mixed with $\mathrm{KBr}$ as a matrix that grounded and pressed with a special press to give a disk of standard diameter. The formed disk was examined in between 4000 and $400 \mathrm{~cm}^{-1}$.

X-ray diffraction (XRD) experiments were conducted on a PAN alytical (Empyrean) X-ray diffraction using $\mathrm{Cu} \mathrm{K}_{\alpha}$ radiation (wave length $0.154 \mathrm{~cm}^{-1}$ ) at an accelerating voltage $40 \mathrm{KV}$, current of $35 \mathrm{~mA}$, scan angle range of $20^{\circ}-70^{\circ}$ and scan step 0:02 .

The surface morphology of DF before and after adsorption of $\mathrm{CV}$ molecules from aqueous solution was analyzed by Scanning Electron Microscopy (SEM) Model Quanta 250 FEG (Field Emission Gun) attached with Energy Dispersive $\mathrm{X}$-ray (EDX) unit analyses, with accelerating voltage $30 \mathrm{KV}$, magnification $14 \mathrm{x}$ up to 1000000 and resolution for Gun.1n), (FEI company, Netherlands), the same using sample in the SEM analysis is used in the qualitative analysis of DF composite by energy dispersive spectroscopy (EDS) in the same microscope, operating at an accelerating voltage of 15 $\mathrm{kV}$.

The physical properties of sorbents were determined by nitrogen adsorption at $77 \mathrm{~K}$ using surface area and porosity analyzer Micromeritics-TriStar II- USA. $\mathrm{N}_{2}$ adsorption isotherms were measured at a relative pressure range $0.0001-$ 0.99 . Then, the adsorption data was employed to determine surface area using Brunauer-Emmett-Teller equation and pore size distribution (including average pore diameter and pore volume) using Barrett- Johner- Halenda equation.

\subsection{Batch Adsorption Experiments}

A batch adsorption method was used in order to determine the kinetics pattern and the needed time to reach equilibrium state, samples of $30 \mathrm{mg}$ of $\mathrm{DF}$ were transported into glass bottles containing $20 \mathrm{~mL}$ of $20 \mathrm{mg} / \mathrm{L} \mathrm{CV}$ solution. Then, using a temperature- controlled shaker, the bottles were placed for a sufficient period to achieve equilibrium at $25^{\circ} \mathrm{C} \pm 0.1$ and a constant speed. The samples were taken from the shaker at predetermined time intervals. Then the adsorbents were separated from the sample using centrifugation at $200 \mathrm{rpm}$ for 5 minutes. Similar procedure was followed to find the effect of various important parameters as effect of $\mathrm{pH}$, the amount of $\mathrm{DF}$, agitation speed, temperature and the contact time between $\mathrm{CV}$ and DF. The absorbance of the supernatant solution was estimated spectrophotometrically at $\lambda_{\max }$ of $590 \mathrm{~nm}$ to determine the residual dye concentration, measured at any time, t. All adsorption experimental tests were made twice.

\subsection{Data analysis}

The following equations are used in calculations [25]:

$$
\begin{aligned}
& \mathrm{R} \%=\frac{\mathrm{C}_{\mathrm{o}}-\mathrm{C}_{\mathrm{t}}}{\mathrm{C}_{\mathrm{o}}} \times 100 \\
& \mathrm{q}_{\mathrm{t}}=\frac{\left(\mathrm{C}_{\mathrm{o}}-\mathrm{C}_{\mathrm{t}}\right) \mathrm{v}}{\mathrm{m}}
\end{aligned}
$$




$$
\mathrm{q}_{\mathrm{e}}=\frac{\left(\mathrm{C}_{\mathrm{o}}-\mathrm{C}_{\mathrm{e}}\right) \mathrm{v}}{\mathrm{m}}
$$

Where $\mathrm{R} \%$, is the percentage removal, $\mathrm{q}_{\mathrm{t}}$ and $\mathrm{q}_{\mathrm{e}}$ are the amount of adsorbed $\mathrm{CV}$ on $\mathrm{DF}$ at time $\mathrm{t}$ and equilibrium, respectively. $\mathrm{C}_{\mathrm{o}}, \mathrm{C}_{\mathrm{t}}$ and $\mathrm{C}_{\mathrm{e}}$ are the concentrations of $\mathrm{CV}$ in the solution $(\mathrm{mg} / \mathrm{L})$ at initial time $(\mathrm{t}=0)$, time $(\mathrm{t})$ and equilibrium, respectively. $\mathrm{V}$ is the volume of solution $(\mathrm{L})$ and $\mathrm{m}$ indicates the mass of adsorbent ( $\mathrm{g}$ ). In this work, our calculations of the considered kinetic and isotherm models were performed using Origin Software Version 9.0 (Microcal Software, Inc.).

\section{RESULTS AND DISCUSSION}

\subsection{Characterization}

From FTIR spectra of DF, Fig. 2a, the broad band in the range 3000-3500 $\mathrm{Cm}^{-1}$ proves presence of $\mathrm{OH}^{-}$of water molecules absorbed into a cellulose fiber structure of DF. The bands in the range of $1000-1300 \mathrm{Cm}^{-1}$ can be attributed to the $\mathrm{C}-\mathrm{OH}$ stretching and $\mathrm{OH}^{-}$bending vibrations which suggest the existence of the hydroxyl group with large amount [26].The peak observed at $1634 \mathrm{~cm}^{-1}$ is the $\mathrm{C}=\mathrm{C}$ stretch of DF. The peak located at $1426 \mathrm{~cm}^{-1}$ could be attributed to carbonyl groups. The bands at 1118 and $1034 \mathrm{~cm}^{-1}$ correspond to the $\mathrm{Si}-\mathrm{O}$ and $\mathrm{Si}-\mathrm{O}-\mathrm{Si}$ vibrations, respectively [27]. By comparing FTIR spectra of DF after adsorption of CV dye, it is clear that the intensity of the bands decrease after adsorption which confirms the adsorption of dye with DF. The diffractogram of DF before adsorption of CV, Fig. 2b, appears sharp and most intense peaks that means increasing of particle size and purity of DF [28]. The morphology of DF surface before adsorption includes images at $1500 \times$, Fig. $3 a$ and 5000x, Fig. 3b magnification. These images show a considerable number of heterogeneous pores and presence of particles in different sizes and sharp edges that promote adhesion of $\mathrm{CV}$ molecules to be strongly adsorbed on cavities and pores of DF surface by means of physisorption. EDS spectra for DF, Fig.3c, confirms the presence of carbon, oxygen, silicon, chloride and potassium elements, which are characteristic of DF. It can be observed that carbon content was found more.

The Langmuir surface area was deduced from the analysis of the isotherms in relative pressure ranging from 0.00-1.0. It is found to be $0.051 \mathrm{~m}^{2} / \mathrm{g}$, the BET surface area is $0.168 \mathrm{~m}^{2} / \mathrm{g}$, the total pore volume $\left(\mathrm{V}_{\text {total }}\right)$ of the $\mathrm{DF}$ was $0.000246 \mathrm{~cm}^{3} / \mathrm{g}$ and the average particle size $357,157.033 \mathrm{~A}^{\circ}$.

\subsection{Adsorption studies}

\subsubsection{Influence of $\mathrm{pH}$ on the adsorption}

For dye adsorption, acidity is very important parameter. Both the adsorbent and adsorbate may have functional groups that can be protonated or deprotonated to produce different surface charges in solutions at different $\mathrm{pH}$, resulting in electrostatic attraction or repulsion between the charged adsorbates and adsorbents [29]. To study the effects of $\mathrm{pH}$ on the adsorption capacity of $\mathrm{DF}$ to $\mathrm{CV}$, experiments were performed using different initial solution $\mathrm{pH}$ values, changing from 2 to 12 , by the addition of $0.1 \mathrm{M} \mathrm{HCl}$ or $0.1 \mathrm{M} \mathrm{NaOH}$ at a fixed initial $\mathrm{CV}$ concentration
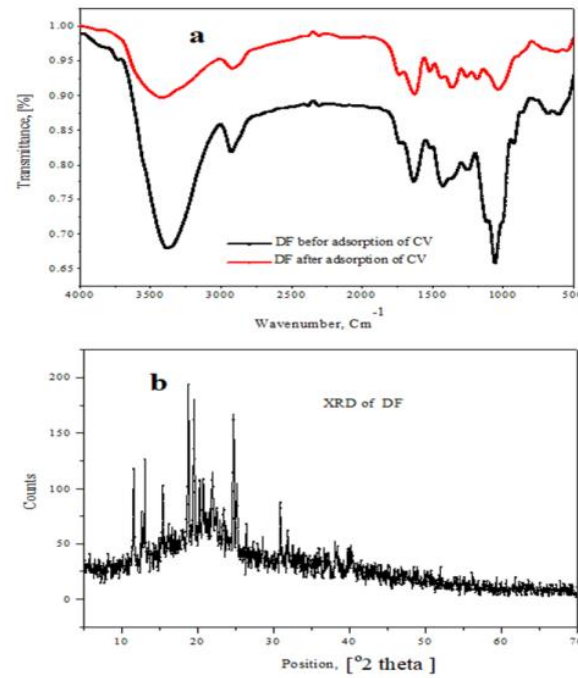

Fig. 2. a-FTIR spectrum of DF b- XRD of DF before adsorption of $\mathrm{CV}$.
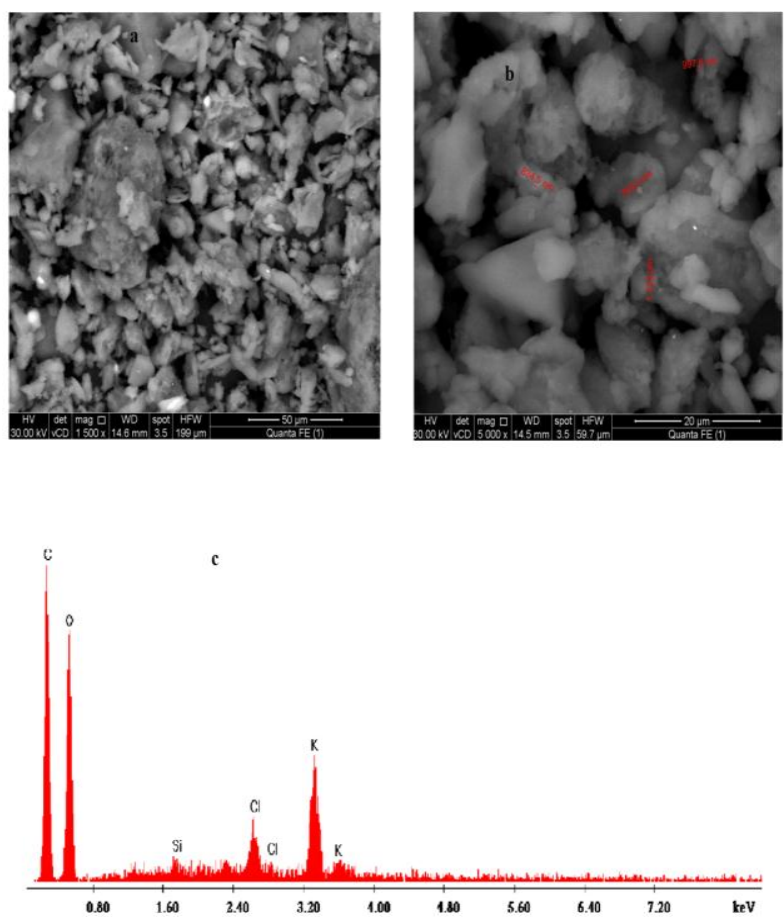

Fig. 3. a-SEM before adsorption of CV with1500x magnification b-SEM before adsorption of CV with 5000x magnification c- EDS spectra for DF.

of $20 \mathrm{mg} / \mathrm{L}$. Each solution was treated with $30 \mathrm{mg}$ of the adsorbent and kept at $25^{\circ} \mathrm{C}$ for one hour as a contact time and at agitation speed of $50 \mathrm{rpm}$. The residual $\mathrm{CV}$ dye concentration was measured. The adsorbed amount of $\mathrm{CV}$ was 
plotted against the values of $\mathrm{pH}$. It is founded that the amount of sorbed $\mathrm{CV} \%$ increased as the $\mathrm{pH}$ value increased from 2 up to 7 and reached to maximum at $\mathrm{pH}=7$ followed by decreasing in the amount of $\mathrm{q}_{\mathrm{t}}$ with increasing $\mathrm{pH}$, Fig. 4a. Since CV dye molecule has different charged states depending on the acidity of the solution; at lower values $\mathrm{pH}$ (of range 12 ), the dye with two of the nitrogen atoms are positively charged. So, lower adsorption was expected due to the competition between excess $\mathrm{H}^{+}$ions with the two cation groups on the $\mathrm{CV}$ dye for adsorption sites causing little interaction between the $\mathrm{CV}$ molecules and DF. With increasing the $\mathrm{pH}$ value (up to 7), extra protons of $\mathrm{CV}$ molecule are lost to the solution leaving only one of the nitrogen atoms positive charges and more $\mathrm{OH}^{-}$ions will accumulate on the adsorbent surface [30]. Meaning that, the electrostatic repulsion between the positively charged dye and the surface of the adsorbent is lowered causing more adsorption of $\mathrm{CV}$ molecules on the surface of adsorbent. In alkaline solution, value of the adsorbed amount of $\mathrm{CV}$ decreases where the excess $\mathrm{OH}^{-}$ions of the solution may attack the electrophilic central carbon of the $\mathrm{CV}$ dye producing triphenyl methanol or carbinol form that lowering the chance $\mathrm{CV}$ molecules to adsorbed on the DF surface. The $\mathrm{pH}$ of sample of $20 \mathrm{ml}$ of $20 \mathrm{mg} / \mathrm{L} \mathrm{CV}$ solution after addition of $0.03 \mathrm{~g}$ of was $6.03 \mathrm{so}$, the other factories were studied at this value to avoid any addition of $\mathrm{NaOH}$ especially the increasing in the removal percentage from $\mathrm{pH}=6.03$ to $\mathrm{pH}=$ 6.03 is lower than $1 \%$.

\subsubsection{Contact time and initial concentration effects of on adsorption process}

In the treatment of wastewater by sorption, the contact time between the sorbent with the organic pollutant is significantly more important. The highly efficiency of the sorbent is recognized when it's able to remove pollutants and reach the equilibrium in a short time [31]. Effects of contact time and initial concentration of $\mathrm{CV}$ on the sorption process were examined with $20 \mathrm{~mL}$ of $\mathrm{CV}$ concentrations of 20, 40, 60, 80 and100 $\mathrm{mg} / \mathrm{L}$ at different times, over the range $0-120 \mathrm{~min}$ whereas the other remaining parameters were kept constants as; $\mathrm{pH}=6.03$, dosage of $\mathrm{DF}=30 \mathrm{mg}$, and agitation speed of $50 \mathrm{rpm}$ at $25^{\circ} \mathrm{C}$, Fig. 4b. From Fig. 4b, values of the adsorbed amount of $\mathrm{CV}$ found to increase in the initial stage of contact time from zero to $60 \mathrm{~min}$ followed by weakly increases that seemed to be a constant up to120 min. This behavior can be explained in the light of the following; in initial stage the unoccupied sites on DF surface are available by large numbers that allows adsorption of $\mathrm{CV}$ molecules fastly and the rate of diffusion of $\mathrm{CV}$ into the interior of the DF increases until all sites on the DF surface become occupied. This time is termed as the equilibrium time and the adsorbed amount of $\mathrm{CV}$ at this time refers to the maximum sorption capacity of DF under these operating conditions. After the equilibrium time, the rate of diffusion of $\mathrm{CV}$ into the interior of the DF becomes slower and/or constant in the later stage where the competition for the available active sites intensifies.

With respected to the effect of $\mathrm{CV}$ concentration, the amount of adsorbed $\mathrm{CV}$ dye increased with increasing the concentration of the dye that means dependence of the adsorption process on the initial concentration of CV. This may be attributed to highly driving force to overcome the resistance for mass transfer at a high initial dye concentration [32].

\subsubsection{Effect of adsorbent dose}

In order to assess the effect of adsorbent amount on $\mathrm{CV}$ removal, different masses on a wide range of 30- $100 \mathrm{mg}$ of DF to $20 \mathrm{~mL} \mathrm{CV}$ solution of concentration $20 \mathrm{mg} / \mathrm{L}$ was carried out where all other operating parameters were kept constant at $\mathrm{pH}=6.03$, contact time for one hour with agitation speed of $50 \mathrm{rpm}$ and $\mathrm{T}=25^{\circ} \mathrm{C}$. The results are depicted in Fig. 4c. It is obvious from Fig. 4c that the removal of $\mathrm{CV}$ decreases. This decrease is likely occurred due to the fixed volume of the used dye may lead to unsaturated adsorption sites during the adsorption process as the adsorbent mass increased [33]. In addition, the total surface area of the adsorbent may be reduced as a result of aggregation of the adsorbent particles as its mass increased that causing increase in the length of the diffusional path. Hence, the optimum dose from $\mathrm{DF}$ was found to be $30 \mathrm{mg} / 20 \mathrm{~mL}$ of $\mathrm{CV}$.

\subsubsection{Effect of agitation speed}

This effect has an important role in the batch adsorption method due to its ability to affecting the distribution of the dye in the bulk solution in addition to the external boundary film [34]. Evaluation the effect of agitation speed on the adsorption process of $\mathrm{CV}$ on DF surface was studied at $25^{\circ} \mathrm{C}$ with an initial weight of $30 \mathrm{mg}$ of DF in $20 \mathrm{~mL}$ of $20 \mathrm{mg} / \mathrm{L}$ of $\mathrm{CV}$ for one hour and $\mathrm{pH}=6.03$. It is founded that the adsorbed amount of $\mathrm{CV}$ are significantly increases from 8.85 up to 11.95 when the agitation speed increased from 20 to 100 rpm, Fig.4d. The removals of adsorbate molecules from aqueous solution onto solid phase surface follow the following mechanism; they are transported to the external surface of the adsorbent through migration from the bulk solution. Then, these molecules are diffusing the boundary layer of the external surface of adsorbent to adsorb on its pores site followed by diffusion into the interior surface of the adsorbent [35]. Then in adsorption of CV on DF, as the agitation speed increases as the resistance of the boundary layer decreases that forcing the adsorbate molecules strongly towards the external surface of adsorbent causing diffusion of adsorbate into the surface of the adsorbent on a large scale. 

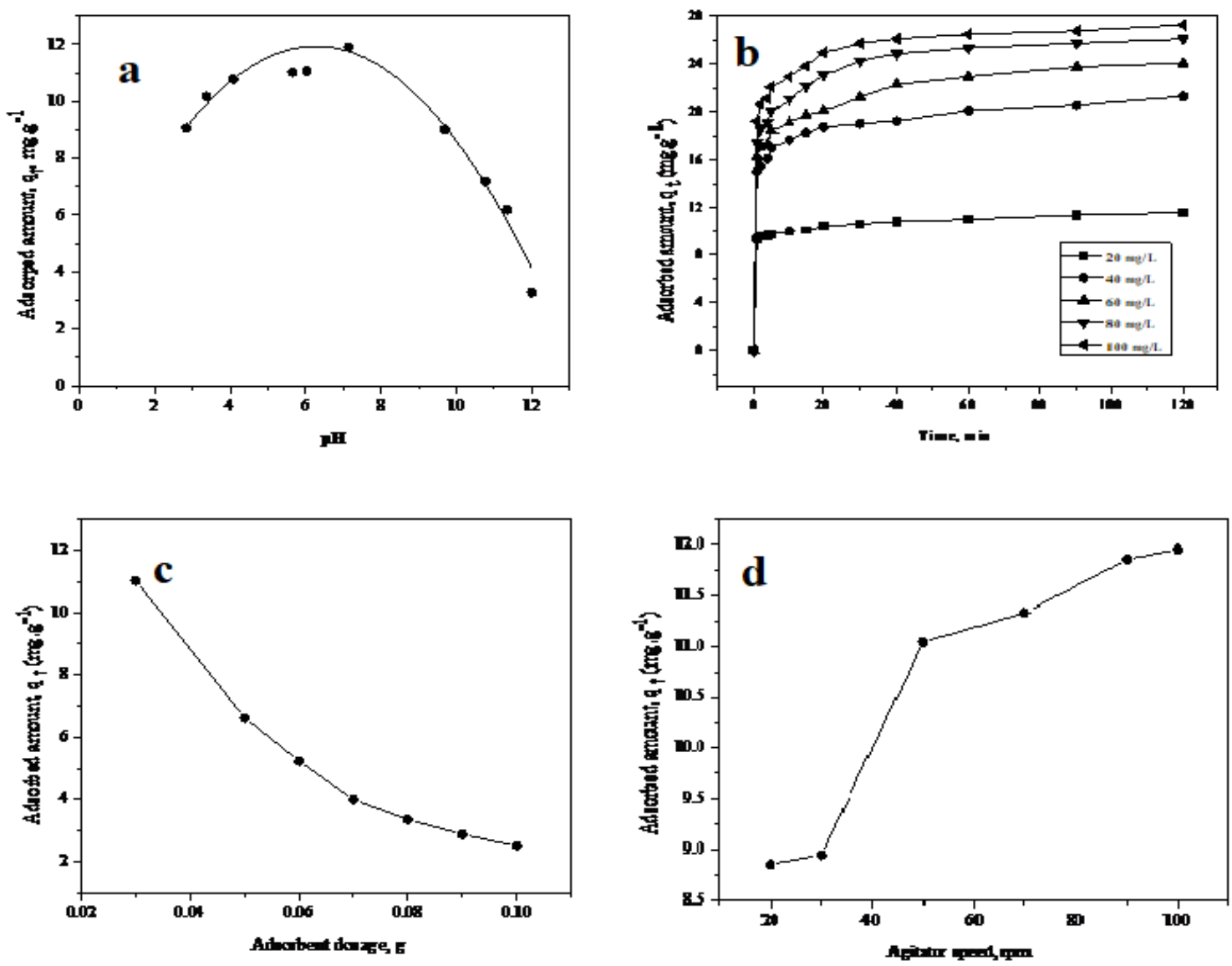

Fig. 4. a- Effect of $\mathrm{pH}$ on the adsorption of $\mathrm{CV}$ onto DF b- Effect of contact time and initial concentration of CV on adsorption of $\mathrm{CV}$ onto DF c- Effect of adsorbent dosage d- Effect of agitator speed on the removal process.

\subsubsection{Effect of temperature and thermodynamic parameters}

Temperature is an important parameter in adsorption processes where it can state the nature of adsorption either exothermic or endothermic process [36]. A series of experiments at $25,30,35,40$ and $45{ }^{\circ} \mathrm{C}$ was investigated to study the effect of temperature on the removal of $20 \mathrm{mg} / \mathrm{L}$ of $20 \mathrm{~mL}$ of CV dye on $30 \mathrm{mg}$ DF within one hour contact time, $\mathrm{pH}=6.03$ and agitation speed $=50 \mathrm{rpm}$. The percentage removal of dye decreased from 82.85 to $58.20 \%$ when the temperature increased from 25 to $45^{\circ} \mathrm{C}$ as shown in Fig. 5a. It is probably because of the weakness of the adsorptive forces between $\mathrm{CV}$ molecules and the active sites on the surface of DF that causes escaping of dye molecules from the DF surface to the bulk solution as the temperature increased. Also, this decreasing in the adsorption indicating that the process is exothermic in nature.

The temperature dependence of the adsorption process is associated with changes in several thermodynamic parameters. These parameters are very important because they give information about the spontaneity of the sorption processes. Parameters such as Gibbs free energy $\left(\Delta \mathrm{G}^{\circ}\right)$, enthalpy $\left(\Delta \mathrm{H}^{\circ}\right)$ and entropy $\left(\Delta \mathrm{S}^{\circ}\right)$ changes for the sorption of $\mathrm{CV}$ dye onto DF can be calculated using the following equations [37-38].

$$
\begin{aligned}
& \operatorname{Ln} K_{d}=-\left(\Delta \mathrm{G}^{\circ} / \mathrm{R} \mathrm{T}\right) \\
& \Delta \mathrm{G}^{\circ}=\Delta \mathrm{H}^{\circ}-\mathrm{T} \Delta \mathrm{S}^{\circ} \\
& \operatorname{Ln~} \mathrm{K}_{\mathrm{d}}=\left(\Delta \mathrm{S}^{\circ} / \mathrm{R}\right)-\left(\Delta \mathrm{H}^{\circ} / \mathrm{RT}\right)
\end{aligned}
$$

Where $\mathrm{R}$ is the general gas constant and its value is 8.314 $\mathrm{J} / \mathrm{mol}$ Kelvin, $\mathrm{T}$ is the absolute temperature (Kelvin) and $\mathrm{K}_{\mathrm{d}}$ refers to distribution coefficient or adsorption equilibrium constant $\left(\mathrm{K}_{\mathrm{d}}=\mathrm{q}_{\mathrm{e}} / \mathrm{C}_{\mathrm{e}}\right)$.

Plotting of $\ln K_{d}$ against $1 / \mathrm{T}$ gives a linear relation with $\mathrm{R}^{2}=$ 0.96, Fig. 5b.Values of $\Delta \mathrm{H}^{\circ}, \Delta \mathrm{S}^{\circ}$ was calculated from the slope and intercept of the plot, respectively. Values of $\Delta \mathrm{G}^{\circ}$ are calculated from equation 5 and listed with the other parameters in Table 1. From Table 1 value of $\Delta \mathrm{H}^{\circ}$ is negative that indicates liberation of the energy during adsorption process (exothermic nature), value of $\Delta \mathrm{S}^{\circ}$ is also negative one that enhancing presence the internal structure of the adsorbent without significant change during the adsorption process. Also, values of $\Delta \mathrm{G}^{\mathrm{o}}$ are negative and lower than $40 \mathrm{KJ} / \mathrm{mol}$, which confirms the physical adsorption, spontaneous nature of this adsorption and reflects the affinity of DF towards CV [3940]. 

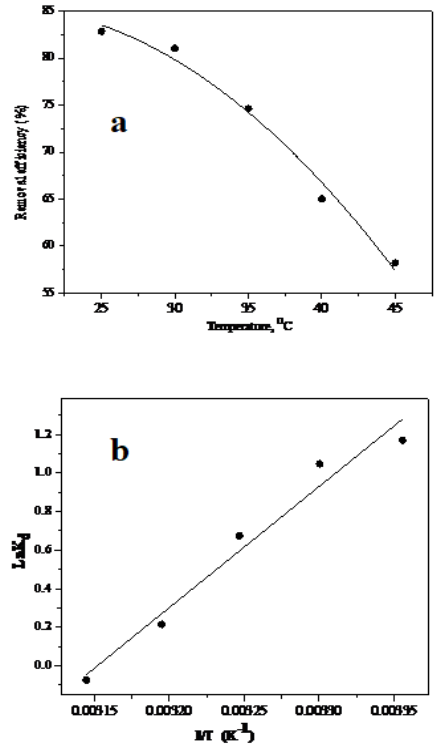

Fig. 5- a. Effect of temperature on adsorption of CV onto DF b- Vant Hoff of adsorption of CV onto DF.

TABLE 1. Thermodynamic parameters for adsorption of CV onto $\mathrm{DF}$.

\begin{tabular}{|ccccc|}
\hline $\begin{array}{c}\text { Temp. } \\
(\mathbf{K})\end{array}$ & $\begin{array}{c}\log \mathbf{K}_{\mathbf{d}} \\
(\mathbf{L} / \mathbf{g})\end{array}$ & $\begin{array}{c}\Delta \mathbf{H}^{\circ} \\
(\mathbf{k J} / \mathbf{m o l})\end{array}$ & $\begin{array}{c}\Delta \mathbf{S}^{\circ} \\
(\mathbf{J} / \mathbf{m o l} \mathbf{K})\end{array}$ & $\begin{array}{c}\Delta \mathbf{G}^{\circ} \\
(\mathbf{k J} / \mathbf{m o l})\end{array}$ \\
\hline 298 & 0.508 & -52.239 & -164.65 & -2.89 \\
303 & 0.455 & & & -2.64 \\
308 & 0.292 & & & -1.72 \\
313 & 0.093 & & & -0.558 \\
318 & -0.032 & & & 0.196 \\
\hline
\end{tabular}

\subsection{Adsorption equilibrium isotherms}

Analysis of data of the equilibrium adsorption by different isotherm models is important to determine the suitable model that can be used for design purposes. In addition, the adsorption isotherm is characterized by certain constants whose values give benefit information about the interaction between adsorbent and adsorbate such as adsorption capacity of the adsorbent and type of adsorption if physisorption or chemisorptions. Three different theoretical models were applied to the obtained experimental data to predict adsorption capabilities of $\mathrm{CV}$ on DF.

\subsubsection{Langmuir isotherm model}

Langmuir determines the maximum adsorption capacity of adsorbent surface to form monolayer. A basic assumption in the Langmuir model is that the adsorbates are adsorbed at a finite number of identical and equivalent sites on the outer surface of the adsorbent forming monolayer sorption with-out interaction between adsorbed molecules (i.e. the surface is homogenous)[41]. The following equation illustrates the linear form of Langmuir isotherm:-

$$
\frac{1}{\mathrm{q}_{\mathrm{e}}}=\frac{1}{\mathrm{Q}}+\frac{1}{\mathrm{bQ}}\left(\frac{1}{\mathrm{C}_{\mathrm{e}}}\right)
$$

Where; $\mathrm{q}_{\mathrm{e}}$ is the amount adsorbed per unit mass of $\mathrm{CV}$ at equilibrium ( $\mathrm{mg} / \mathrm{g}), \mathrm{Q}$ is the theoretical monolayer capacity of the adsorbent $(\mathrm{mg} / \mathrm{g}), \mathrm{C}_{\mathrm{e}}$ is the equilibrium concentration $(\mathrm{mg} / \mathrm{L})$ and $\mathrm{b}$ is the sorption equilibrium constant (called Langmuir constant) related to the energy of adsorption $(\mathrm{L} / \mathrm{mg})$. From $\mathrm{b}$ value, the equilibrium parameters $\left(\mathrm{R}_{\mathrm{L}}\right)$ can be calculated. It is a dimensionless constant and considers one of the essential characteristics of the Langmuir model and can be calculated from the following equation [42]:-

$$
\mathrm{R}_{\mathrm{L}}=\frac{1}{1+\mathrm{bC}_{0}}
$$

Where $\mathrm{C}_{0}$ is the highest initial concentration of $\mathrm{CV}$. It is known that, the type of isotherm indicates according the value of $\mathrm{R}_{\mathrm{L}}$ as follows; irreversible $\left(\mathrm{R}_{\mathrm{L}}=0\right)$, favorable $\left(0<\mathrm{R}_{\mathrm{L}}<1\right)$, linear $\left(\mathrm{R}_{\mathrm{L}}=1\right)$, and/or unfavorable $\left(\mathrm{R}_{\mathrm{L}}>1\right)$.

From plotting of $1 / \mathrm{q}_{\mathrm{e}}$ against $1 / \mathrm{C}_{\mathrm{e}}$, Fig. $6 \mathrm{a}$, a straight line was appeared with correlation coefficient $=0.954$. The maximum value of $\mathrm{Q}$ and $\mathrm{b}$ value were determined from the intercept and slope of Fig. 6a, respectively and collected in Table 2. The calculated $\mathrm{R}_{\mathrm{L}}$ value is less than 1 and more than zero value indicating that the sorption isotherms is favorable.

\subsubsection{Freundlich isotherm}

The Freundlich isotherm is commonly used to describe the intensity of adsorption of the adsorbent for the adsorbate (multilayer adsorption). This model assumes that as the adsorbate concentration increases, its concentration on the surface of adsorbent will also increase. The logarithmic form of the Freundlich equation can be represented as the following [43]:-

$$
\log \mathrm{q}_{\mathrm{e}}=\log \mathrm{K}+\frac{1}{\mathrm{n}} \log \mathrm{C}_{\mathrm{e}}
$$

Where $\mathrm{K}$ is an indicator constant for adsorption capacity of the adsorbent $(\mathrm{mg} / \mathrm{g})$ and $1 / \mathrm{n}$ is a function of the strength of adsorption in the adsorption process which depends on the nature of the both adsorbate and adsorbent [44]. It is reported that, value of $n$, between 1 and 10 (i.e. $1 / n<1$, become closer to zero) refers to the surface is more heterogeneous than homogeneous and the adsorption is favorable [45]. From plots of $\log \mathrm{q}_{\mathrm{e}}$ against $\log \mathrm{C}_{\mathrm{e}}$, a straight line with correlation coefficient 0.915 that indicates fitting of the isotherm to the experimental data, Fig. 6 b. Value of $\mathrm{K}$ was calculated from the intercept of the straight line, Fig. 6 b, as 8.52 then DF is thought to have a reasonable ability to sorbs CV dye. Value of $\mathrm{n}$ was determined from the slope as 2.64 which refers to the heterogeneity of the surface.

\subsubsection{Dubinin- Radushkevich (D-R) isotherm}

Both the characteristic porosity of the adsorbent and the 
heterogeneity of the surface energies from the adsorption can be recognized from applying the $D-R$ isotherm to the data [46]. The D-R equation is more general than the Langmuir model because it doesn't assume a homogeneous surface, a constant sorption potential, or an absence of sterichindrance between adsorbed and incoming particles [47].The linear form of $\mathrm{D}-\mathrm{R}$ isotherm is presented as the following equation:-

$$
\ln q_{\mathrm{e}}=\ln \mathrm{q}_{\mathrm{m}}-\mathrm{K}_{\mathrm{D}-\mathrm{R}} \varepsilon^{2}
$$

Where $\mathrm{q}_{\mathrm{m}}$ is the theoretical isotherm saturation capacity ( $\mathrm{mg} / \mathrm{g}), \mathrm{K}_{\mathrm{D}-\mathrm{R}}$ is the D-R isotherm constant and $\boldsymbol{\varepsilon}$ is another constant for D-R isotherm [48] which is described as;

$$
\varepsilon=\mathrm{RT} \ln \left(1+\frac{1}{\mathrm{C}_{\mathrm{e}}}\right)
$$

Where $\mathrm{T}$ is the solution temperature $(\mathrm{K}), \mathrm{R}$ is the gas constant $(8.314 \mathrm{~J} / \mathrm{mol} \mathrm{K})$ and $\mathrm{C}_{\mathrm{e}}$ is the concentration of adsorbate at equilibrium $(\mathrm{mg} / \mathrm{L})$. Values of $\mathrm{K}_{\mathrm{D}-\mathrm{R}}$ and $\mathrm{q}_{\mathrm{m}}$ represent the slope and intercept of the plot of $\mathrm{Inq}_{\mathrm{e}}$ against $\varepsilon^{2}$. From the value of $\mathrm{K}_{\mathrm{D}-\mathrm{R}}$, means free energy, $\mathrm{E}$, of adsorption per molecule of the adsorbate when it is transferred to the surface of the solid from infinity in solution $(\mathrm{kJ} / \mathrm{mol})$ can be calculated as follows [49];

$$
\mathrm{E}=\frac{1}{\left(2 \mathrm{~K}_{\mathrm{D}-\mathrm{R}}\right)^{1 / 2}}
$$

It is stated that, the adsorption process can be considered a physical adsorption when the value of $\mathrm{E}$ is below $8(\mathrm{~kJ} / \mathrm{mg})$ and chemical adsorption when value of $E$ is located in the range of $8-16(\mathrm{~kJ} / \mathrm{mg})$. From Fig. $6 \mathrm{c}$, the value of $\mathrm{R}^{2}$ is 0.901 , reveals fitting the experimental data with the $D-R$ isotherm model. The calculated value of $\mathrm{E}$ is $0.637(\mathrm{~kJ} / \mathrm{mol})$ that gives indication on physisorption type between $\mathrm{CV}$ and DF.

(a)

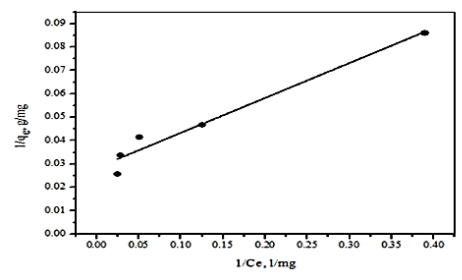

(b)

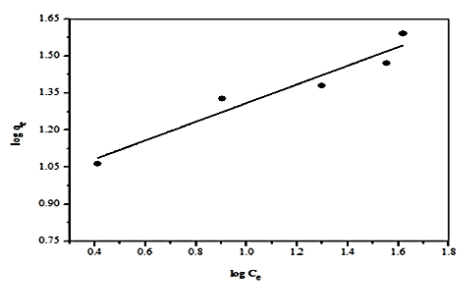

(c)

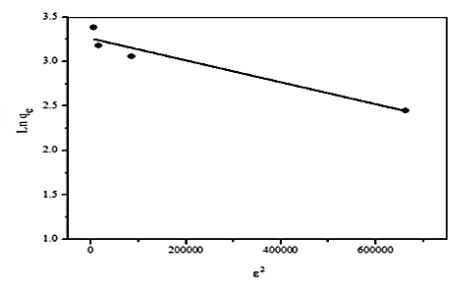

Fig. 6. a- Langmuir isotherm b- Freundlich isotherm c- Dubinin-Radushkevich.
Table 2. The parameters of Langmuir, Freundlich and Dubinin-Radushkevich isotherms at $298 \mathrm{~K}$.

\begin{tabular}{|lccc|}
\hline \multicolumn{1}{|c}{ Isotherms } & $R^{2}$ & Parameters & Values \\
& & \multicolumn{2}{c|}{ (constant) } \\
\hline \multirow{2}{*}{ Langmuir } & \multirow{3}{*}{0.954} & $\mathrm{~b}(\mathrm{~L} / \mathrm{mg})$ & 0.18 \\
& & $\mathrm{Q}(\mathrm{mg} / \mathrm{g})$ & 35.26 \\
& & $\mathrm{R}_{\mathrm{L}}(\mathrm{Unitless})$ & 0.050 \\
\hline Freundlich & $\mathbf{0 . 9 1 5}$ & $\mathrm{K}(\mathrm{mg} / \mathrm{g})$ & $\mathbf{8 . 5 2}$ \\
& & $\mathrm{n}$ & 2.64 \\
\hline Dubinin- & $\mathbf{0 . 9 0 4}$ & $\mathrm{q}(\mathrm{mg} / \mathrm{g})$ & 25.96 \\
Radushkevich & & $\mathrm{E}(\mathrm{kJ} / \mathrm{mol})$ & 0.637 \\
\hline
\end{tabular}

From Table 2, values of correlation coefficient indicates fitting Langmuir isotherm with the experimental data with highly degree than Freundlich and D-R models.

\subsection{Adsorption kinetic modeling}

The importantly of the kinetic study is stating the rate and mechanism of the adsorption process. The rate of the adsorption is considered a good factor beside adsorption capacity for testing the availability of material to be used as an adsorbent; where the used adsorbent should have a fast adsorption rate and a large adsorption capacity [37].The adsorption mechanism was investigated to state the ratelimiting step to optimize the design of adsorbents and adsorption conditions. The rate-limiting step can be one or more of the following steps; 1 - transportation of the dye from the bulk solution to the exterior surface of sorbent (called film or surface diffusion) 2- diffusion of dye molecules into the interior of sorbent particles (called intraparticle diffusion) 3 interior adsorption of dye onto sites of the sorbent. This third step is very rapid then; the adsorption process will be controlled by one of the two other steps or mixing of them. The obtained kinetic data for adsorption of CV onto DF was analyzed using different kinetic models as Lagergren's pseudo first-order kinetic model, pseudo second-order kinetic model and intra-particle diffusion model.

\subsubsection{Pseudo-first order kinetic model}

This model is presented by the Lagergren equation, which describe the rate of adsorption according the adsorption capacity. The integrated form of this equation can be represented as:

$$
\log \left(q_{e}-q_{t}\right)=\log q_{e}-\left(\frac{k_{1}}{2.303}\right) t
$$

Where $\mathrm{q}_{\mathrm{e}}$ is the amount adsorbed at equilibrium $(\mathrm{mg} / \mathrm{g}), \mathrm{q}_{\mathrm{t}}$ is the amount adsorbed at time $\mathrm{t}(\mathrm{mg} / \mathrm{g})$ and $\mathrm{k}_{1}$ is the rate constant of pseudo first- order sorption $(\mathrm{g} / \mathrm{mg} \min )$. Values of $\mathrm{k}_{1}$ and $\mathrm{q}_{\mathrm{e}}$ were calculated from slopes and intercepts of plots of log 
$\left(\mathrm{q}_{\mathrm{e}^{-}} \mathrm{q}_{\mathrm{t}}\right)$ with time, respectively, Fig.7a and listed in Table 3. From Table 3, the adsorption of CV onto DF doesn't follow the pseudo first-order kinetic model although the correlation coefficients values are high considerable (in the range from 0.94 to 0.99 ), the calculated $q_{e}$ values don't close to the experimental ones and lower.

\subsubsection{Pseudo-second-order kinetic model}

Using pseudo-second-order kinetic rate equation, the rate of sorption of CV onto DF was analyzed. The linear pseudosecond-order equation in the integrated form may be represented as the following;

$$
\frac{\mathrm{t}}{\mathrm{q}_{\mathrm{t}}}=\frac{1}{\mathrm{k}_{2} \mathrm{qe}^{2}}+\frac{1}{\mathrm{q}_{\mathrm{e}}} \mathrm{t}
$$

Where $\mathrm{k}_{2}$ is the rate constant of pseudo second-order sorption (gm/g min). From plots of $\mathrm{t} / \mathrm{q}_{\mathrm{t}}$ against $\mathrm{t}$ of Eq.14, straight lines should be obtained or (would be noticed) if the pseudosecond-order kinetics is applicable. From the slope and intercept of these plots, values of $\mathrm{q}_{\mathrm{e}}$ and $\mathrm{k}_{2}$ can be calculated, respectively. Plots of $\mathrm{t} / \mathrm{q}_{\mathrm{t}}$ versus $\mathrm{t}$, Fig. $7 \mathrm{~b}$, gives straight lines. Values of $\mathrm{k}_{2}$ and $\mathrm{q}_{\mathrm{e}}$, Table 3. Values of the calculated adsorbed amount of $\mathrm{CV}$ ( $\mathrm{q}_{\mathrm{e}}$ calc.) are found to be closer to the experimental one $\left(\mathrm{q}_{\mathrm{e}}\right.$ exp.) with very higher value of correlation coefficients $(\geq 0.998)$ for pseudo-second-order kinetic model. Then, the adsorption of CV onto DF is more favorably by the pseudo-second order model and this reinforcing the applicability of this model.

\subsubsection{The intra-particle diffusion model}

This model gives a relationship between the amounts of dye adsorbed at time $\mathrm{t}, \mathrm{q}_{\mathrm{t}}(\mathrm{mg} / \mathrm{g})$ with the square root of the time $\mathrm{t}^{\frac{1}{2}}$ rather than with the contact time $\mathrm{t}$. This model neglected the film diffusion (or boundary layer diffusion) and takes in account the intraparticle diffusion step as the only rate controlling step. The linear form equation according Weber and Morrisis [50]:-

$$
\mathrm{q}_{\mathrm{t}}=\mathrm{k}_{\mathrm{id}} \mathrm{t}^{\frac{1}{2}}+\mathrm{C}_{\mathrm{i}}
$$

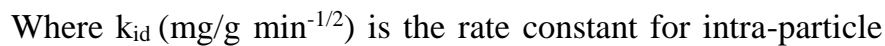
diffusion at different initial concentrations, $t$ is the time (min) and $\mathrm{C}_{\mathrm{i}}(\mathrm{mg} / \mathrm{g})$ is constant gives information about the thickness of the boundary layer: large the value of $\mathrm{C}_{\mathrm{i}}$ suggests high boundary layer effect (i.e. the resistance to the external mass transfer will increase). From plot of $\mathrm{q}_{\mathrm{t}}$ versus $\mathrm{t}^{\frac{1}{2}}$ if only a straight line passing by the origin obtained this means that the intra-particle diffusion is the only mechanism controlling the sorption process and if multi-linear plots are obtained then, more than one step take place in the adsorption process [5153]. The experimental data at various concentrations of initial CV were applied to the Weber and Morris model when other operating parameters are fixed as elucidate in Fig. 11c from which two parameters have been determined from the slopes and intercepts of Fig. $7 \mathrm{c} ; \mathrm{k}_{\mathrm{id}}$ and $\mathrm{C}_{\mathrm{i}}$ respectively, Table 3. From Fig. 7c, the lines are linear but don't pass through the origin that means the adsorption of CV onto DF isn't controlled by intraparticle diffusion only. Besides that, values of $\mathrm{C}_{\mathrm{i}}$ are higher than zero and increases with increasing initial $\mathrm{CV}$ concentration that reflects increasing the resistance to dye molecules of the layer of liquid surrounding the particle of DF. Then we can be concluded that the adsorption process is a two-step mechanism involving film or surface diffusion and intraparticle diffusion.

(a)
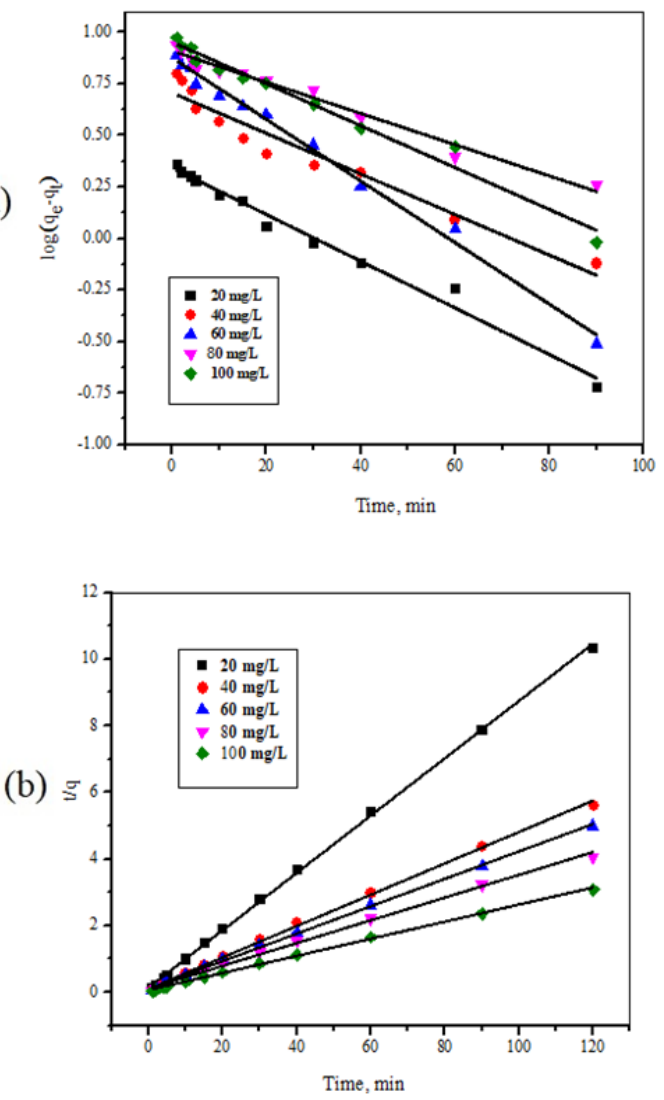

(c)

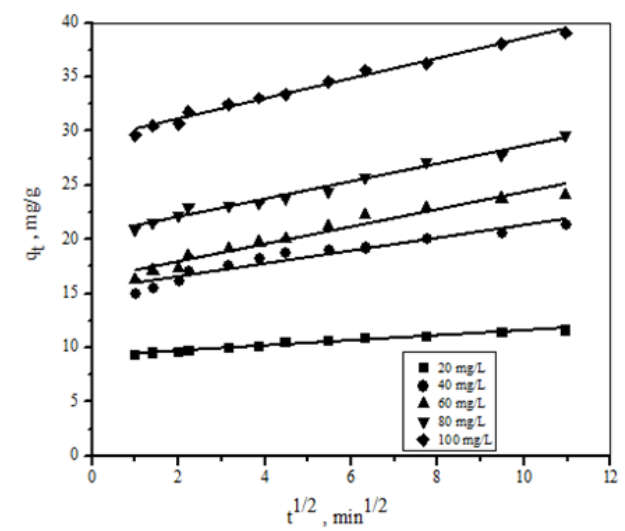

Fig. 7. a-Pseudo-first order model b- Pseudo-second order model c- The intra-particle diffusion model. 
International Journal of Engineering Research and Technology. ISSN 0974-3154 Vol.13, No.4 (2020), pp. 675-685

(C) International Research Publication House. https://dx.doi.org/10.37624/IJERT/13.4.2020.675-685

Table 4. Maximum adsorption capacity of various low-cost adsorbents with CV.

\begin{tabular}{|c|c|c|c|c|c|c|c|c|c|c|}
\hline \multirow{2}{*}{$\begin{array}{l}\text { Conc. } \\
\text { (mg/L) }\end{array}$} & \multicolumn{3}{|c|}{ Pseudo-first-order } & \multicolumn{3}{|c|}{ Pseudo-second-order } & \multicolumn{4}{|c|}{ Intraparticle diffusion } \\
\hline & $\mathbf{R}^{2}$ & $\begin{array}{l}\text { qe, calc. } \\
(\mathrm{mg} / \mathrm{g})\end{array}$ & $\begin{array}{c}\mathrm{k}_{1} \\
\left(\mathrm{~min}^{-1}\right)\end{array}$ & $\begin{array}{c}\text { K } \\
(\mathrm{g} / \mathrm{mg} \text { min })\end{array}$ & $\begin{array}{c}\text { qe, calc. } \\
(\mathrm{mg} / \mathrm{g})\end{array}$ & $\begin{array}{l}q_{e}, \text { exp. } \\
(\mathrm{mg} / \mathrm{g})\end{array}$ & $\overline{\mathbf{R}^{2}}$ & $\begin{array}{c}\mathbf{k}_{\mathrm{id}} \\
\left(\mathrm{mg} / \mathrm{g} \mathrm{min}^{1 / 2}\right)\end{array}$ & $\overline{\mathbf{R}^{2}}$ & $\begin{array}{c}\mathbf{C}_{\mathbf{i}} \\
(\mathrm{mg} / \mathrm{g})\end{array}$ \\
\hline 20 & 0.982 & 2.18 & 0.025 & 0.055 & 11.61 & 11.61 & 0.999 & 0.234 & 0.975 & 9.23 \\
\hline 40 & 0.944 & 5.04 & 0.022 & 0.023 & 21.24 & 21.33 & 0.998 & 0.594 & 0.915 & 15.35 \\
\hline 60 & 0.991 & 7.48 & 0.034 & 0.016 & 24.33 & 24.07 & 0.998 & 0.801 & 0.945 & 16.32 \\
\hline 80 & 0.975 & 8.05 & 0.017 & 0.011 & 29.28 & 29.61 & 0.995 & 0.817 & 0.981 & 20.42 \\
\hline 100 & 0.972 & 8.93 & 0.023 & 0.012 & 39.06 & 39.05 & 0.998 & 0.929 & 0.985 & 29.26 \\
\hline
\end{tabular}

\subsection{Comparison of capacities of various low-cost adsorbents for $C V$}

The maximum adsorption capacities of different types of lowcost adsorbents are used for removal of $\mathrm{CV}$ available in the literature were reported in Table 4 to make comparison with the maximum sorption capacity of DF used in this work for $\mathrm{CV}$. It shows that the performance of DF to remove CV from an aqueous solution is an excellent process.

Table 4. maximum adsorption capacity of various low-cost adsorbents with $\mathrm{CV}$.

\begin{tabular}{|lcc|}
\hline \multicolumn{1}{|c}{ Adsorbents $Q_{\max }(\mathrm{mg} / \mathrm{g})$} & \\
References & & \\
\hline Acacia nilotica leaves (RVM) & 33 & {$[54]$} \\
Citrulluslanatus rind & 11.9 & {$[55]$} \\
Bottom ash & 12.1 & {$[56]$} \\
zeolites synthesized from fly ash (ZFA) & 19.6 & {$[57]$} \\
zeolites synthesized from bottom Ash (ZBA) & 17.6 & {$[57]$} \\
Leaf biomass of Calotropisprocera & 4.14 & {$[58]$} \\
Agricultural waste cocoa shell & 43.5 & {$[59]$} \\
Bagasse fly ash & 26.32 & {$[60]$} \\
Raw kaolin & 44.87 & {$[61]$} \\
Acacia nilotica leaves (RVM) & 33.0 & {$[62]$} \\
Jute fibre carbon & 27.99 & {$[63]$} \\
CAL BC & 40.49 & {$[24]$} \\
DF & 35.26 & This \\
& & study \\
\hline
\end{tabular}

\section{6. Conclusions}

In this study, employing of DF as available, environmentally safe and low-cost sorbent for the removal of CV from an aqueous solution improved that DF is an effective sorbent. The adsorption process reached to the equilibrium state after
$60 \mathrm{~min}$. It is increased as the dosage of CV increased that enhances the interactions between CV and DF. In addition, it is found to be effective in the acidic medium $(\mathrm{pH}<7)$, at room temperature $\left(25^{\circ} \mathrm{C}\right)$, increased when the agitation speed increased and the optimum dose of DF was $30 \mathrm{mg}$ per liter of $\mathrm{CV}$. The adsorption process was spontaneous and exothermic. Also, the adsorption follows Langmuir with $\mathrm{Q}_{\max }$ of 35.26 $\mathrm{mg} / \mathrm{g}$ at $25^{\circ} \mathrm{C}$ and Freundlich isotherms (with lower degree than Langmuir) compared with D-R isotherm. The Lagergren first-order model, the pseudo-second order model and the intraparticle diffusion model were used to analyze the kinetics data. It is best fitted to the pseudo-second order model. Analysis of mechanism reveals that the adsorption process is a two-step mechanism involving surface (or film) diffusion with intraparticle diffusion.

\section{REFERENCES}

[1] V. K. Gupta, I. Ali, T.A. Saleh, A. Nayak, and S. Agarwal, "Chemical treatment technologies for wastewater recycling" -An overview, $R S C A d v$. vol. 2, pp. 6380-6388, 2012.

[2] R. P. F. Melo, E. L. Barros Neto, M. C. P. A. Moura, T. N. Castro Dantas, A. A. Dantas Neto, and H. N. M. Oliveira, "Removal of direct yellow 27 dye using animal fat and vegetable oil-based surfactant", $J$. Water Process Eng. vol. 7, pp. 196-202, 2015.

[3] S. E. Rizk, and M. M. Hamed, "Batch sorption of iron complex dye, naphthol green $\mathrm{B}$, from wastewater on charcoal, kaolinite, and tafla", Desalination and Water Treatment. vol. 56, pp. 1536-1546, 2014.

[4] A. Ż. Ferenc, and M. Biziuk, "Solid phase extraction technique -trends opportunities and applications", Polish J. of Environ Stud. vol. 15, pp. 677-690, 2006.

[5] S. J. T. Pollard, G. D. Fowler, C. J. Sollars, and R. Perry, "Low-cost adsorbents for waste and waste water treatment: areview", Sci. Total Environ. vol. 116, pp. 31-52, 1992.

[6] M. S. El-Geundi, "External mass transport processes during the adsorption of basic dyestuffs onto Maize Cob", Adsor. Sci. Technol. vol. 7, pp. 124-132, 1990.

[7] M. C. Somasekhara Reddy, "Removal of direct dye 
from aqueous solutions with an adsorbent made from tamarind fruit shell, an agricultural solid waste", J. Sci. Ind. Res. vol. 65, pp. 443-446, 2006.

[8] C. Namasivayam, and D. Kavitha, "Removal of Congo Red with water by adsorption onto activated carbon prepared from coir pith, an agricultural solid waste", Dyes Pigm, vol. 54, pp. 47-58, 2002.

[9] P. S. Kumar, S. Ramalingham, C. Senthamarai, M. Niranjanaa, P. Vijayalakshmi, and S. Sivanesan, "Adsorption of dye from aqueous solution by cashew nut shell: Studies on equilibrium isotherm., kinetics and thermodynamics of interactions", Desalination. vol. 261, pp. 52-60, 2010.

[10] A. E. Ofomaja, and Y.S. Ho, "Equilibrium sorption of anionic dye from aqueous solution by palm kernel fibre as sorbent”, Dyes Pigments. vol. 74, pp. 60-66, 2007.

[11] C. Namasivayam, and N. Kanchana, "Waste banana pith as adsorbent for color removal from waste waters", Chemosphere. vol. 25, pp. 1691-1705, 1992.

[12] P. K. Malik, "Dye removal from wastewater using activated carbon developed from sawdust: adsorption equilibrium and kinetics", J. Hazard Mater. vol. B113, pp. 81-88, 2004.

[13] B. H. Hameed, "Equilibrium and kinetic studies of methyl violet sorption by agricultural waste", J. Hazard Mater. vol. 154, pp. 204-12, 2008.

[14] P. Sharma, H. Kaur, M. Sharma, and V. Sahore, "A review on applicability of naturally available adsorbents for the removal of hazardous dyes from aqueous waste", Environ Monit Assess. vol. 183, pp. 151-195, 2011.

[15] Y. S. Al-Degs, M. I. El-Barghouthi, A. A. Issa, M. A. Khraisheh, and G. M. Walker, "Sorption of $\mathrm{Zn}(\mathrm{II})$, $\mathrm{Pb}(\mathrm{II})$, and $\mathrm{Co}(\mathrm{II})$ using natural sorbents: equilibrium and kinetic studies", Water Res. vol. 40, pp. 26452658, 2006.

[16] K. O. Adebowale, I. E. Unuabonah, and BI. O. Owolabi, "The effect of some operating variables on the adsorption of lead and cadmium ions on kaolinite clay", J. Hazard Mater. vol. 134, pp. 130-139, 2006.

[17] S. Babel, and T. A. Kurniawan, "Low-cost adsorbents for heavy metals uptake from contaminated water: a review", J. Hazard. Mater. vol. B97, pp. 219-243, 2003.

[18] V.J. Inglezakis, M. D. Loizidou, and H. P. Grigoropoulou, "Equilibrium and kinetic ion exchange studies of $\mathrm{Pb}^{2+}, \mathrm{Cr}^{3+}, \mathrm{Fe}^{3+}$ and $\mathrm{Cu}^{2+}$ on natural clinoptilolite", Water Res. vol. 36, pp. 2784-92, 2002.

[19] S. Kocaoba, and T. Akyuz, "Effects of conditioning of sepiolite prior to cobalt and nickel removal", Desalination. vol. 181, pp. 313-318, 2005.

[20] H. M. Burkill, "The useful plants of West Tropical Africa", 2nd (Edn), Royal Botanical garden, Kew, vol. 4, pp. 371-373, 1997.

[21] M. H. Hetta, and N.Z. Yassin, "Comparative studies on hypocholesterolemic effect of different fractions of Hyphaene thebaica (Doum) in experimental animals", Die Pharmazie -An International Journal of Pharmaceutical Sciences. vol. 61, pp. 230-232, 2006.
[22] M. H. Hetta, N. Z. Yassin, and M.A. El Shaer, "Effect of Hyphaene thebaica on the spermatogenesis of male rats", Egypt. Med. J. N.R.C. vol. 4, pp. 35-39, 2005.

[23] AL. Adaya, H. Bdliya, M. Bitrus, D. Fanjaji, MB. Eaton, and M. Gambo, Hidden harvest project.In: Research Series,Compiled by 11ED and HNNCP. vol.3, pp. 14-27, 47-53, 1977.

[24] P. Monash, R. Niwas, and G. Pugazhenthi, "Utilization of ball clay adsorbents for the removal of crystal violet dye from aqueous solution", Clean Techn. and Environ. Policy. Vol. 13, pp. 141-151, 2011.

[25] M. Ghaedi, Sh. Heidarpour, S. N. Kokhdan, R. Sahraie, A. Daneshfar, and B. Brazesh, "Comparison of silver and palladium nanoparticles loaded on activated carbon for efficient removal of Methylene blue: Kinetic and isotherm study of removal process", Powder Technol. vol. 228, pp. 18-25, 2012.

[26] P. V. Nidheesh, R. Gandhimathi, S. T. Ramesh, T. S. Anantha Singh, "Kinetic analysis of crystal violet adsorption on to bottom ash", Turkish J. Eng. Env. Sci. vol. 36, pp. 249 - 262, 2012.

[27] R. Lapuente. F. Cases, P. Garcésc, E. Morallóna, and J. L. Vázqueza, "A voltammetric and FTIR-ATR study of the electropolymerization of phenol on platinum electrodes in carbonate medium: Influence of sulfide", J. Electroanal. Chem. vol. 451, pp. 163-171, 1998.

[28] U. I. Gaya, E. Otene and A. H. Abdullah, "Adsorption of aqueous $\mathrm{Cd}$ (II) and $\mathrm{Pb}$ (II) on activated carbon nanopores prepared by chemical activation of doum palm shell", Springer Plus. vol. 4, pp. 458, 2015.

[29] Z. Wu, H. Joo, and K. Lee, " Kinetics and thermodynamics of the organic dye adsorption on the mesoporous hybrid xerogel", Chem. Eng. J. vol. 112, pp. 227-236, 2005.

[30] E. Q. Adams, and L. Rosenstein, "THE COLOR AND IONIZATION OF CRYSTAL-VIOLET”, J. Am. Chem. Soc. vol. 36, pp. 1452-1473, 1914.

[31] M. M. Hamed, "Sorbent extraction behavior of a nonionic surfactant, Triton X-100, onto commercial charcoal from low level radioactive waste", J. Radioanal. Nucl. Chem. vol. 302, pp. 303-313, 2014.

[32] K. S. Bharathi, and S. T. Ramesh, "Removal of dyes using agricultural waste as low-cost adsorbents: a review”, Appl Water Sci. vol. 3, pp. 773-790, 2013.

[33] N. F. Cardoso, R.B. Pinto, E.C. Lima, T. Calvete, C. V. Amavisca, B. Royer, M. L. Cunha, T. H. M. Fernandes, and I. S. Pinto, "Removal of remazol black B textile dye from aqueous solution by adsorption", Desalination. vol. 269 , pp. 92-103, 2011.

[34] G. Crini, H. N. Peindy, F. Gimbert and C. Robert, "Removal of C.I. Basic Green 4 (Malachite Green) from Aqueous Solutions by Adsorption Using Cyclodextrin-Based Adsorbent: Kinetic and Equilibrium Studies," Separation and Purification Technology, vol. 53, pp. 97-110, 2007.

[35] H. Patel, R. and T. Vashi, "Adsorption of Crystal Violet Dye onto Tamarind Seed Powder", E-J Chem, vol. 7, pp. 975-984, 2010.

[36] M. A. M. Salleh, D. K .Mahmoud, W. A. W. A. 
Karim, and A . Idris, "Cationic and anionic dye adsorption by agricultural solid wastes: a comprehensive review", Desali, Vol. 280, pp. 1-13, 2011.

[37] B. El - Gammal, S. S. Metwally, H.F. Aly, and A. E. Enein, "Verification of double-shell model for sorption of cesium, cobalt, and europium ions on polyacrylonitrile-based Ce (IV) phosphate from aqueous solutions", Water Treat, vol. 46, pp. 124-138, 2012.

[38] Uma, S. Banerjee, and Y. C. Sharma, "Equilibrium and kinetic studies for removal of malachite green from aqueous solution by a low cost activated carbon", J.Indust and Engin. Chem,vol. 19, pp. 1099-1105, 2013.

[39] H. E. Boujaady, A. E. Rhilassi, M. B. Ziatni, R. E. Hamri, A. Taitai, and J. L. Lacout, "Removal of a textile dye by adsorption on synthetic calcium phosphates" „Desalination, vol. 27, pp. 10-16, 2011.

[40] E. Eren, and B. Afsin, "Investigation of a basic dye adsorption from aqueous solution onto raw and pretreated bentonite surfaces", Dyes and Pigments, vol. 76, pp. 220-225, 2008.

[41] I. Langmuir, "THE CONSTITUTION AND FUNDAMENTAL PROPERTIES OF SOLIDS AND LIQUIDS. PART I. SOLIDS", J. Am. Chem. Soc, vol. 38, pp. 2221-2295, 1916.

[42] M. Abbas, S. Kaddour, and M. Trari, "Kinetic and equilibrium studies of cobalt adsorption on apricot stone activated carbon", J. Ind. Eng. Chem, vol. 20, pp. 745-751, 2014.

[43] M. M. Hamed. S. M. Yakout, and H. S. Hassan, Radio. Chim. Acta, vol. 102, pp. 1017, 2014.

[44] D. Georgiev, B. Bogdanov, Y. Hristov, and I. Markovska. "The Removal of $\mathrm{Cu}$ (II) Ions from Aqueous Solutions on Synthetic Zeolite NaA", // World Acad. Sci. Eng. and Tech., vol. 64, pp. 751-755, 2012.

[45] G. McKay, H. S. Blair, and J. R. Gardner, "The Adsorption of Dyes on Chitin", Part I. Equilibrium Studies, J. Appl. Polym. Sci, vol. 27, pp. 3043-3057, 1982.

[46] M. M. Dubinin, E. D. Zaverina, and L. V. Radushkevich, "Sorption and Structure of Active Carbons I. Adsorption of Organic Vapors", J. Phy. Chem, vol. 21, pp. 1351-1362, 1947.

[47] T. Salman, F. A. Temel, N. G. Turan, and Y. Ardali," Adsorption of lead (II) ions onto diatomite from aqueous solution: Mechanism, isotherm and kinetic studies", Global Nest J, vol. 18, pp. 1-10, 2016.

[48] K. Saltalt, A. Sarı, M. Aydın, "Removal of ammonium ion from aqueous solution by natural Turkish (Y1ldizeli) zeolite for environmental quality", J. Hazard. Mater, vol. 141, pp. 258-263, 2007.

[49] S. Kundu and A. K. Gupta., "Arsenic Adsorption onto Iron Oxide-Coated Cement (IOCC): Regression Analysis of Equilibrium Data with Several Isotherm Models and Their Optimization", Chem. Eng. J, vol.122, pp. 93-106, 2006.

[50] W. J. Weber, and J. C. Morris, "Kinetics of Adsorption on Carbon from Solution", Am. Soc. Civil. Eng, vol.
89, pp. 31-60, 1963.

[51] J. C. P. Vaghetti, E. C. Lima, B. Royer, N. F. Cardoso, B. Martins, and T. Calvete, "Pecan Nutshell as Biosorbent to Remove Toxic Metals from Aqueous Solution", Sep. Sci. Technol, vol. 44, pp. 615-644, 2009.

[52] G. Annadurai, R. S. Juang, and D. J. Lee, "Use of cellulose-based wastes for adsorption of dyes from aqueous solutions", J. Hazard. Mater. Vol. 92, pp. 263274, 2002.

[53] F. C. Wu, R. L. Tseng, and R. S. Juang, "Adsorption of dyes and phenols from water on the activated carbons prepared from corncob wastes", Environ. Technol, vol. 22, pp. 205-213, 2001.

[54] A. L. Prasad, and T. Santhi., "Adsorption of hazardous cationic dyes from aqueous solution onto Acacia nilotica leaves as an eco friendly adsorbent", Sustain Environ. Res, vol. 22, pp. 113-122, 2012.

[55] K.S. Bharathi, and S.T. Ramesh, "Equilibrium, thermodynamic and kinetic studies on adsorption of a basic dye by Citrullus lanatus rind", Iran. J. Energy Environ, vol. 3, pp. 23-34, 2012.

[56] R. Gandhimathi, S. T. Ramesh, V. Sindhu, and P. V. Nidheesh, "Single and Tertiary System Dye Removal from Aqueous Solution Using Bottom Ash: Kinetic and Isotherm Studies", Iran J. Energy Environ, vol. 3, pp. 35-45, 2012.

[57] C. R. B. Tharcila, C. I. Juliana, P. M. Carina, and A. F. Denise, Electro. J. Chem, vol. 5, pp. 179, 2013.

[58] H. Ali and S. K. Muhammad, "Biosorption of Crystal Violet from Water on Leaf Biomass of Calotropis procera," J. Environ. Sci. Technol, vol. 1, pp. 143150, 2008.

[59] S. Senthilkumar, P. Kalaamani, K. Porkodi, P. R. Varadarajan, and C.V. Subburaam, "Adsorption of dissolved Reactive red dye from aqueous phase onto activated carbon prepared from agricultural waste", Bioresour Technol, vol. 97, pp. 1618-1625, 2006.

[60] I. D. Mall, V. C. Srivastava and N. K. Agarwal, "Removal of Orange-G and Methyl Violet dyes by adsorption onto bagasse fly ash-kinetic study and equilibrium isotherm analyses", Dyes and Pigments, vol. 69 , pp. 210-223, 2006.

[61] B. K. Nandi, A. Goswami, A. K. Das, B. Mondal, and M. K. Purkait, "Kinetic and Equilibrium Studies on the Adsorption of Crystal Violet Dye using Kaolin as an Adsorbent". Sep. Sci. Technol, vol. 43, pp. 1382-1403, 2008.

[62] L. P. Ashly, and S. Thirumalisamy, "Adsorption of hazardous cationic dyes from aqueous solution onto Acacia nilotica leaves as an eco-friendly", Sustain. Environ. Res, vol. 22, pp. 113-122, 2012.

[63] A. Porkodi, and K. V. Kumar, "Equilibrium, kinetics and mechanism modeling and simulation of basic and acid dyes sorption onto jute fiber carbon: Eosin yellow, malachite green and crystal violet single component systems", J. Hazard. Mater, vol. 143, pp. 311-327, 2007. 